Final Progress Report

Division of Materials Sciences and Engineering, SC-131

Office of Basic Energy Sciences

U.S. Department of Energy

19901 Germantown Road

Washington, D.C. 20874 - 1290

Attention: Dr. Yok Chen

Program Manager

on

\title{
FRACTURE AND SUBCRITICAL DEBONDING IN THIN LAYERED STRUCTURES: \\ EXPERIMENTS AND MULTI-SCALE MODELING
}

\author{
DOE Grant: DE-FG03-95ER45543-A006 \\ Submitted by: \\ Department of Materials Science and Engineering \\ Stanford University \\ Stanford, CA 94305 - 2205 \\ Principal Investigator: Professor Reinhold H. Dauskardt
}

STANFORD UNIVERSITY

August 2005 


\section{INTRODUCTION}

The objective of our DOE research program is to study the fundamental mechanisms of fracture and subcritical debonding in thin-layered structures, MEMS devices, and other modern technologies that involve interfaces with dissimilar materials. Particular emphasis is placed on subcritical crack growth or debonding under selected environmental, cyclic loading, and temperature conditions. The objective is to identify and model salient mechanisms responsible for subcritical crack growth, to study their temperature dependence and environmental sensitivity, and to develop multi-scale mechanistic and computational models to quantitatively describe such failure processes. The ultimate aim of the proposed study is to provide a fundamental basis from which the mechanical reliability of layered structures may be understood, and to provide guidelines for the development of technologically relevant layered material structures with optimum resistance to fracture and subcritical debonding.

In our DOE program unique experimental and multi-scale computational modeling capabilities have been developed to study fracture and subcritical cracking in thin-film structures. Our program to date at Stanford has been extremely fruitful, starting with an emphasis on the mechanisms of fracture and fatigue crack-growth in structural ceramics at high temperature [e.g. 1, 2], and in bulk glasses in selected moist environments where we demonstrated the presence of a true mechanical fatigue effect in some glass compositions [3]. We have also reported on the effects of environment and fatigue loading on subcritical cracking that effects the reliability of MEMS and other micro-devices using novel micro-machined silicon specimens $[4,5,6,7,8]$.

In the last renewal of our program, the fundamental mechanisms of adhesion and subcritical cracking in a range of thin-film structures was initiated. This work has helped lay the groundwork for quantitative studies of interface fracture resistance (or adhesion) in thin-film device structures, and introduced new adhesion test metrologies that are now becoming an industry standard for the microelectronic industry $[4,9,10,11,12]$. Multiscale modeling efforts to describe fracture and debonding processes in thin-film structures were also commenced $[13,14,15,16]$.

A summary of our progress in the program is described below. Most of the work is available in journal publications which contain detailed descriptions. 


\subsection{Program Objective}

The objective of our current research is to study the fundamental mechanisms of fracture and subcritical debonding in thin-layered structures, MEMS devices, and other modern technologies that involve interfaces with dissimilar materials. Particular emphasis will be placed on subcritical crack growth or debonding under selected environmental, cyclic loading, and temperature conditions. The objective is to identify and model salient mechanisms responsible for subcritical crack growth, to study their temperature dependence and environmental sensitivity, and to develop multi-scale mechanistic and computational models to quantitatively describing such failure processes. The ultimate aim of the proposed study is to provide a fundamental basis from which the mechanical reliability of layered structures may be understood, and to provide guidelines for the development of technologically relevant layered material structures with optimum resistance to fracture and subcritical debonding.

\subsection{Experimental Subcritical Crack-Growth Facilities}

An important part of our DOE program has been to develop experimental facilities to measure fracture and subcritical crack-growth behavior under both monotonic and cyclic applied loads in controlled temperature, gaseous and liquid environments. We have developed unique experimental capabilities to reliably measure both long (> $3 \mathrm{~mm}$ ) and "microstructurally-small" subcritical crack-growth behavior in even the most brittle ceramic and thin-film structures at controlled temperatures (up to $1300^{\circ} \mathrm{C}$ ) and in hostile aqueous chemical environments. These facilities and techniques are preeminent nationally representing a unique combination of high resolution mechanical testing equipment together with full environmental and temperature control. They allow unparalleled optical access to the test specimen making high resolution images of the near-tip fracture process possible.

Our mechanical testing capabilities have recently focused on quantitative and reproducible adhesion and time dependent subcritical debonding measurements of interfaces in thin-film structures [see e.g. 9, 10, 13]. The micromechanical testing facilities for thin-film adhesion studies include high-resolution servomotor and piezoelectric actuators with sub-nanometer resolution. They are equipped with in situ AFM imaging capabilities and full environmental control. They have also been employed by our group for adhesion studies of thin metallic films in magnetic recording head devices, and thin polymer films (various BCB's, polyimide, UF epoxies) for high density 
microelectronic packaging applications [see e.g. 17,18,19]. These facilities have allowed us to systematically examine the role of salient interface parameters, including chemistry, morphology, adjacent layer composition and microstructure, on the adhesion and moisture sensitivity of debonding processes as described below.

Our most recent development for high precision subcritical crack-growth studies was to develop a side-face electrical resistance technique using thin conducting metallic films for specimens containing thin layered structures [11]. The methods employed are not straight forward as the specimen sizes are physically small and the films as well as the silicon substrates are frequently conductive or semiconductors. This requires the use of non-conducting passivation layers between the specimen and the metallic film. We describe a method using a thin $\mathrm{SiO}_{2}$ passivation layer and a titanium film deposited on the side face of double cantilever beam (DCB) fracture specimens which have thinfilm structures sandwiched between silicon substrates. The resulting crack gauge is shown to exhibit a linear change in resistance with crack extension and excellent long term stability. Unprecedented crack velocity measurements (as low as $\sim 10^{-12} \mathrm{~m} / \mathrm{s}$, to our knowledge the lowest ever reported) have been achieved with this technique using standard environmental controls (Figure 1). The measured crack length and growth rates are compared to those measured using compliance techniques, which yield growth rates of $\sim 10^{-10} \mathrm{~m} / \mathrm{s}$ for this study. 


\section{Debonding of Cu / ALD - TaN Interface}
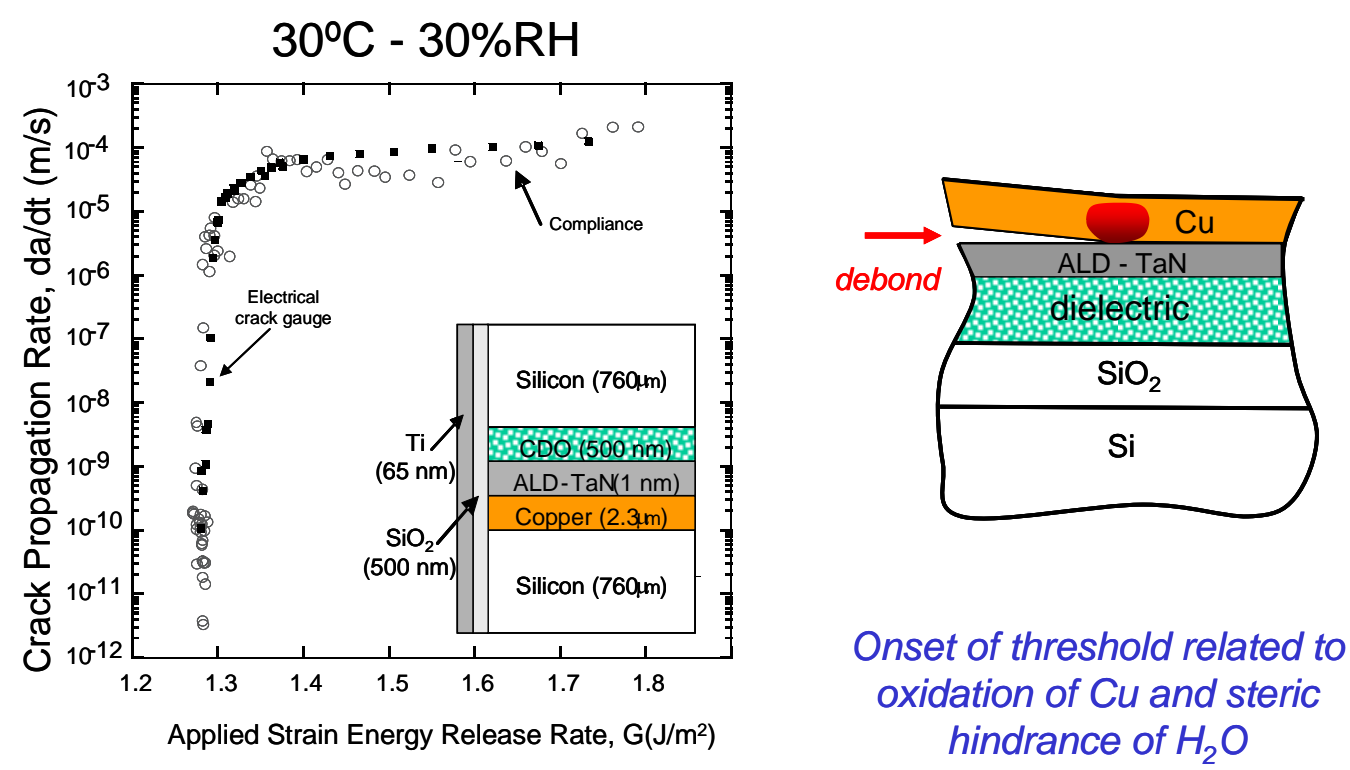

Figure 1: $\quad$ Moisture assisted subcritical crack growth behavior for interfacial cracking of the $\mathrm{Cu} / \mathrm{TaN}$ interface showing a comparison of crack velocities measured using the electrical crack gauge and load relaxation compliance techniques as a function of the applied G. The crack gauge data allowed crack velocities to be determined to nearly two orders of magnitude lower than the compliance analysis [11].

We have also recently studied the effects of loading point friction and applied loading geometry on four-point bend adhesion measurements [12]. The 4-point bend method has become a widely established technique to quantitatively examine the cohesive and adhesive fracture energies of thin-film structures. To date, friction effects together with other salient loading parameters have received little attention and have not been systematically studied. Technologically relevant interconnect thin film structures containing either carbon doped oxide or thermal oxide low-k dielectrics and selected barrier layers were prepared. Specimens were tested in four-point bending to determine the dependence of the measured fracture energy, $G_{c}$, on loading parameters and specimen geometry including the loading rate, load point separation, and specimen surface condition. $G_{c}$ values were observed to increase as the distance between the inner and outer loading pins was decreased beyond a certain distance. $G_{c}$ values also showed a marked increase with increasing applied displacement rate. These trends are shown to be due to a combination of loading point friction and stress corrosion mechanisms. Additional experimental data are presented which demonstrate the effects 
of contact point lubrication and surface roughening in order to further qualify the role of loading point friction. Good practice testing guidelines are suggested to improve the accuracy and precision of four-point bend measurements and described in a recent paper [12].

\subsection{Adhesion and Subcritical Debonding in Thin-Film Structures}

Thin-film structures produced using microelectronic deposition and fabrication procedures allow unprecedented control of the stack structure, layer composition and thickness, interface chemistry and morphology, and in some cases, the residual stress state. These structures provide ideal model systems for fundamental studies of fracture and subcritical debonding where the interface properties can be controlled with precision. The results are important for a range of emerging electronic, photonic and biological technologies.

\section{Effect of Aqueous Solution pH on Subcritical Crack Growth in Thin-Film}

Structures: We are particularly interested in studying the mechanisms of subcritical debonding of interfaces between brittle glasses and barrier layers in complex chemical environments. The intent of this part of our program is to characterize and model the subcritical crack growth behavior of both dense and nanoporous methylsilsesquioxane (MSSQ) and other organosilicate thin-films in complex chemical environments that may typically be encountered during device processing or in service. The mass transport of chemically active species and reaction rate models were utilized and developed to elucidate the molecular mechanisms responsible for subcritical crack growth.

Despite the propensity for thin-film glasses to fracture at nearly all levels of integration and processing, there is a surprising lack of experimental crack velocity data and fundamental understanding of the effect solution $\mathrm{pH}$ on the rate of crack growth. In the present study we revealed how $\mathrm{pH}$ in non-buffered solutions affects the rate of crack growth in methylsilsesquioxane (MSSQ) nanoporous thin-film glasses [22]. The effect of hydroxide ion concentration on accelerating crack growth rate together with the existence of a well defined crack growth plateau velocity resulting from the transport of hydroxide ions to the crack tip was demonstrated (Figure 2). The observed plateau velocity occurs when the crack growth is limited by the diffusion of hydroxide ions to the crack tip. While the transport of hydroxide ions has been postulated [20], we believe that 
this is the first reported experimental observation of a clearly defined crack growth plateau resulting from transport of hydroxide ions to the crack tip.

\section{Subcritical Cracking in Non-Buffered Solutions}
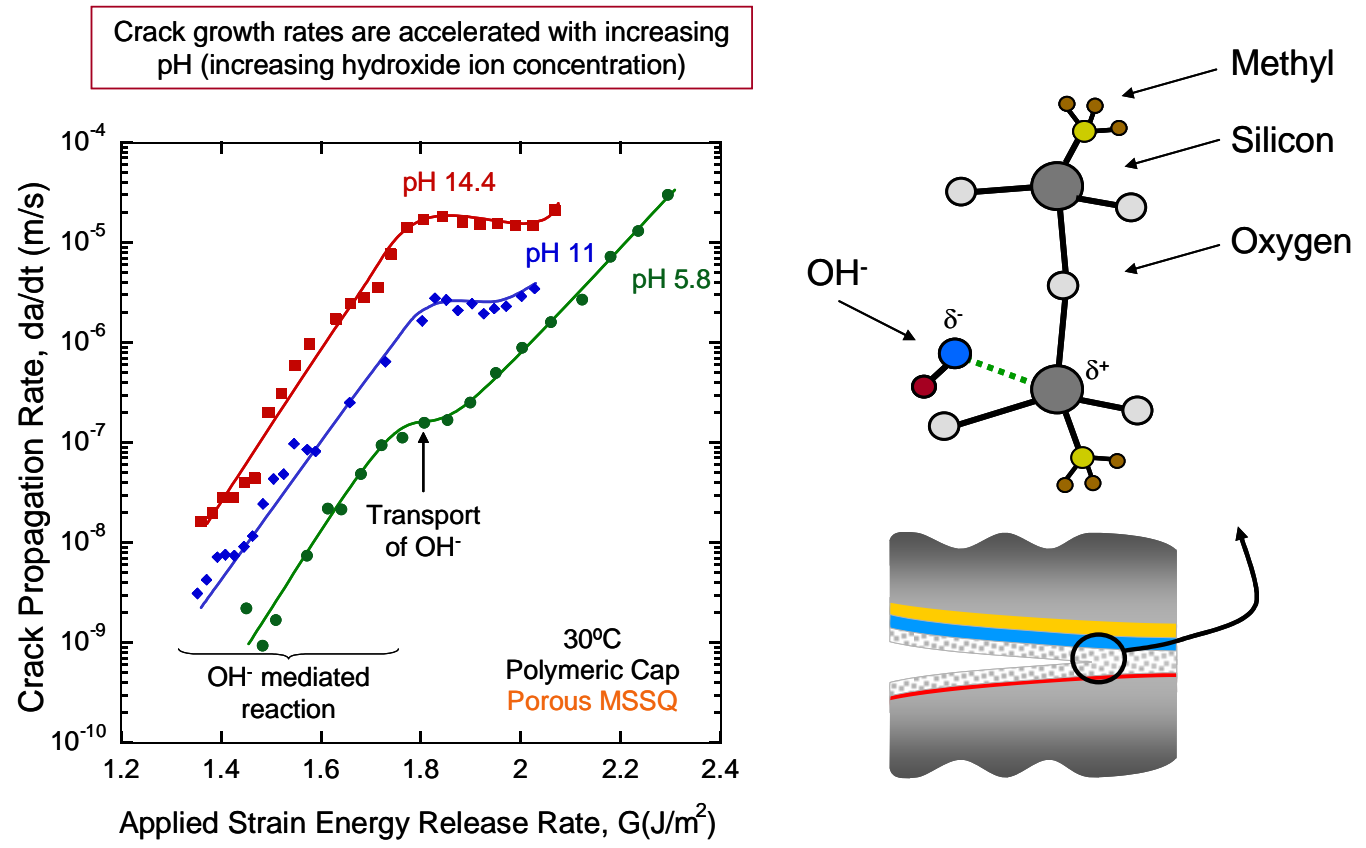

Figure 2: Subcritical crack growth behavior of porous MSSQ with organic polyarylene hardmask cap in strong $\mathrm{NaOH}$ solutions and water [22]. The reaction between Si-O crack tip bonds and hydroxide ions dominates growth for $G<1.75 \mathrm{~J} / \mathrm{m}^{2}$ and a transport regime is apparent at for $\mathrm{G}>1.8 \mathrm{~J} / \mathrm{m}^{2}$.

Conventional chemical reaction rate and transport limited crack growth models were both found to over predict the velocities by as much as 6 orders of magnitude. We propose that the deviation from theory results from a significantly different concentration of hydroxide ions in the nanoscopically confined region of fluid behind the crack tip compared to that of the bulk solution. Mechanisms to account for differences between the crack tip chemistry and the bulk solution are proposed and described in detail in the publication [22].

Effect of Hydrogen Peroxide Aqueous Solutions: This research demonstrates for the first time anomalously high crack-growth rates of nanoporous methylsilsesquioxane (MSSQ) thin-films in weakly acidic hydrogen peroxide solutions [21]. Hydrogen peroxide solutions are of significant technological interest since many thin-film device structures 
may be exposed to such environments either during processing or even in service. Results vary markedly from those predicted by solution $\mathrm{pH}$, as acidic environments are generally considered to inhibit cracking. We elucidate the fundamental chemical interactions and molecular mechanisms responsible for the anomalous behavior.

\section{Accelerated Cracking of Fragile Nanoporous Glass Layers}
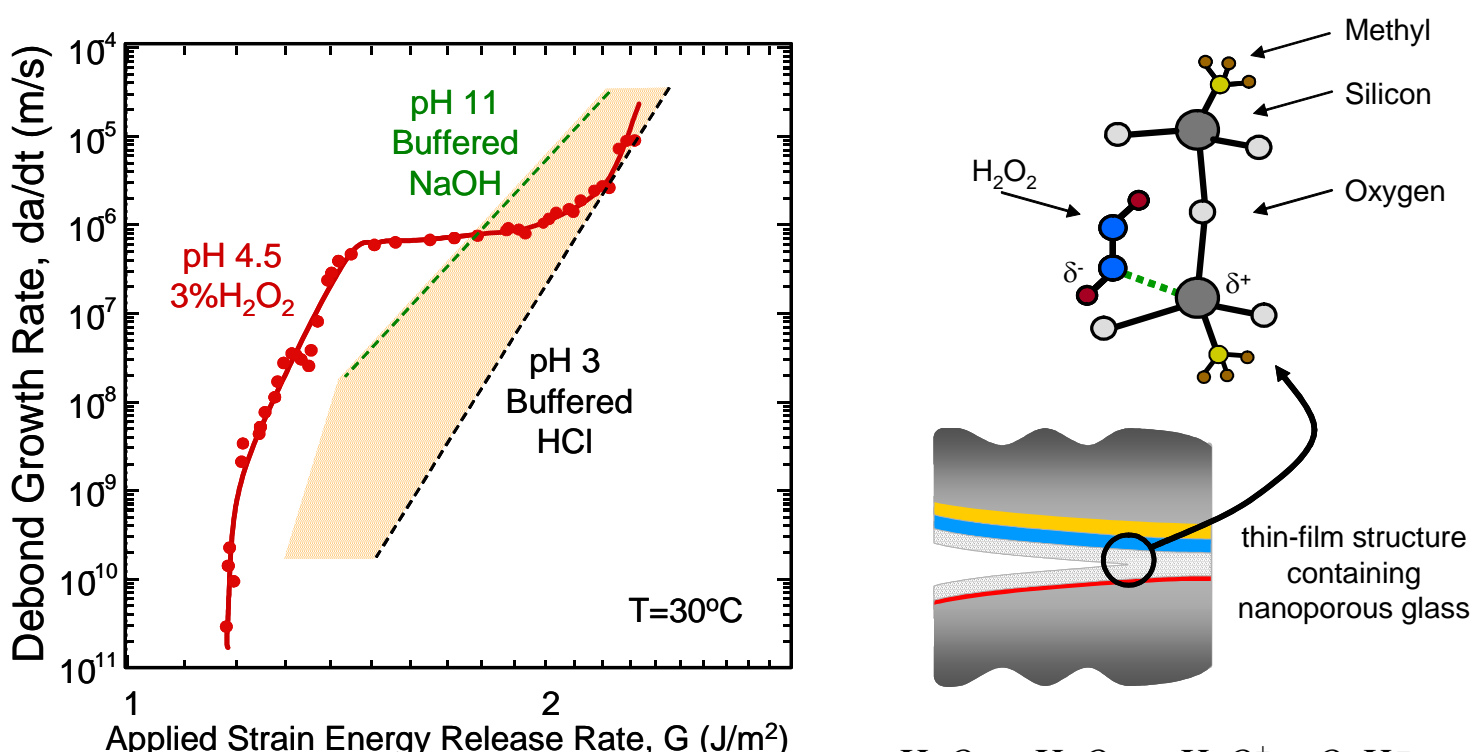

STANFORD

MATERLASSCIENG

E. Guyer and R. H. Dauskardt (Nature Materials) - 2003

$$
\mathrm{H}_{2} \mathrm{O}_{2}+\mathrm{H}_{2} \mathrm{O} \leftrightarrow \mathrm{H}_{3} \mathrm{O}^{+}+\mathrm{O}_{2} \mathrm{H}^{-}
$$

Figure 3: Subcritical crack growth behavior showing the significant effect of buffered solution $\mathrm{pH}$ on cracking in porous MSSQ with polymer cap. XPS fracture path analysis revealed cohesive failure of the MSSQ.

Generalized failure criteria for thin-film structures based on solution $\mathrm{pH}$ alone must be made with great care, therefore, as weakly acidic $\mathrm{H}_{2} \mathrm{O}_{2}$ solutions accelerate growth rates well beyond those expected for acidic solutions (Figure 3). At low values of $\mathrm{G}$, the hydrogen peroxide molecules react vigorously with the crack tip bonds and significantly accelerate cracking rates. Even more unexpectedly, an anomalous transport limited regime near $\sim 10^{-6} \mathrm{~m} / \mathrm{s}$ was observed at intermediate values of $\mathrm{G}$. This transport limited region persists until the crack tip is essentially void of $\mathrm{H}_{2} \mathrm{O}_{2}$ molecules. At crack velocities above $\sim 10^{-6} \mathrm{~m} / \mathrm{s}$ the solution retains its acidic character and the $\mathrm{v}-\mathrm{G}$ curve for this environment is consistent with that of an equivalent $\mathrm{pH}$ solutions. This work represented the discovery of a new chemical reaction rate process that governs accelerated cracking in $\mathrm{H}_{2} \mathrm{O}_{2}$ environments. As noted above, the implications of these 
results are of extreme technological importance as $\mathrm{H}_{2} \mathrm{O}_{2}$ is commonly encountered during device processing or even in service.

The effect of $\mathrm{H}_{2} \mathrm{O}_{2}$ concentration is shown in Figure 4 (a). The dashed lines in the figure represent the predicted behavior assuming first order reaction kinetics. The transport regime is clearly consistent with the model, however, a well defined reaction regime is not apparent. In fact, the data for $\mathrm{H}_{2} \mathrm{O}_{2}$ concentration of $1.5,3$, and 10 wt.\% collapse onto a single curve. Here, the crack flanks sterically hinder the molecular species from reaching the crack tip near $0.8 \mathrm{~J} / \mathrm{m}^{2}$ and growth rates drop precipitously with decreasing $\mathrm{G}$.

An interesting effect is realized when sodium hydroxide is added to the $\mathrm{H}_{2} \mathrm{O}_{2}$ solution (Figure 4 (b)). The crack growth behavior at high values of $G$ is consistent with that of a basic environment, as again, the $\mathrm{H}_{2} \mathrm{O}_{2}$ molecules will be transport limited from reaching the crack tip. With decreasing $\mathrm{G}$, cracking behavior resembles that of the $3 \%$ $\mathrm{H}_{2} \mathrm{O}_{2}$ solution, however, near $0.9 \mathrm{~J} / \mathrm{m}^{2}$ a marked acceleration is observed. This phenomenon is due to the general corrosion of the MSSQ crack flanks. In other words, when the molecules begin to be come sterically hindered from reaching the crack tip and growth rates decrease, the corrosion of the surface allows the $\mathrm{H}_{2} \mathrm{O}_{2}$ molecules to reach the crack tip, accelerating crack growth. The molecules again become sterically hindered, which decreases growth rates until the corrosion again allows the molecules to reach the crack tip. This continues until the reaction threshold for the $\mathrm{Si}-\mathrm{O}$ crack tip bonds and $\mathrm{H}_{2} \mathrm{O}_{2}$. This has a significant effect on cracking particularly at low values of $\mathrm{G}$.

Cracking in the Lithographically Patterned Structures: We have begun to address the effects of patterned device structures as opposed to blanket films on adhesion and debonding. The intention is to develop characterization metrologies and a fundamental understanding of the physics and mechanics governing adhesive properties in complex thin-film structures representative of device, sensor and actuator technologies. Based on these capabilities, the goal is to develop technologically relevant design guidelines that govern adhesive and cohesive fracture properties in ultra-thin patterned films with regard to their feature size, aspect ratios, materials, etc. 

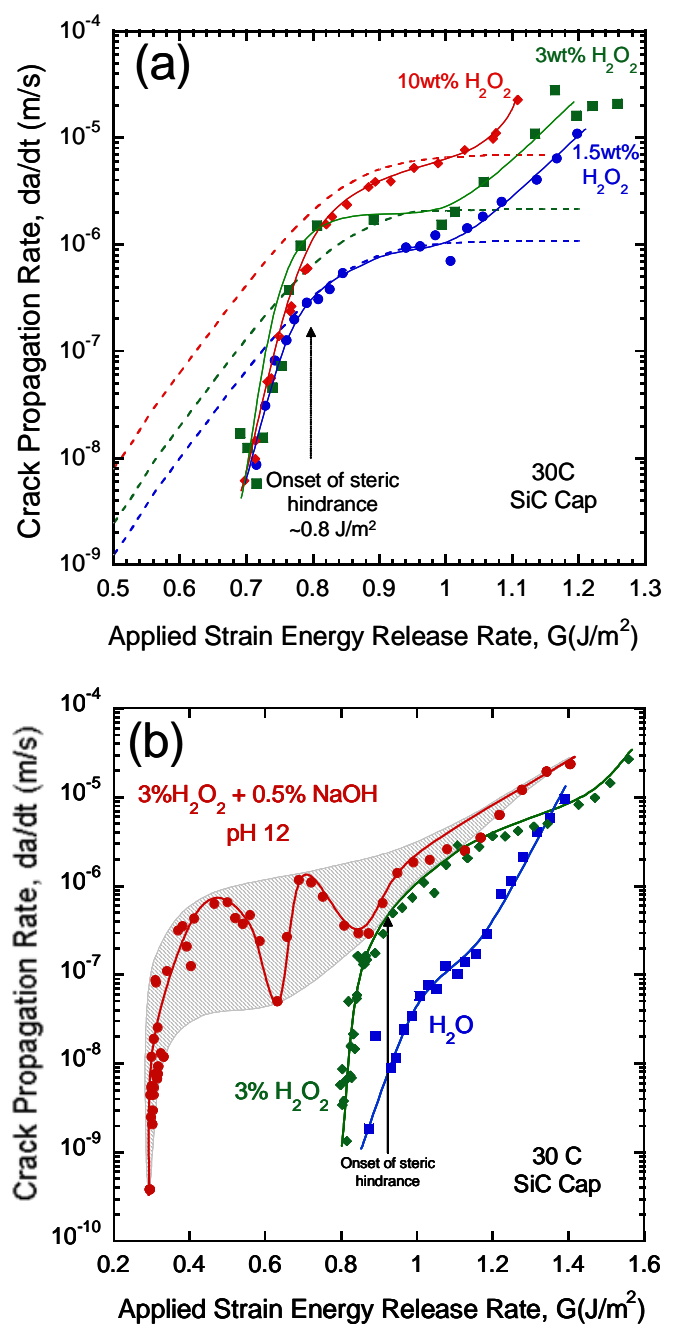

Figure 4: (a) Effect of increasing hydrogen peroxide concentration. The onset of steric hindrance is clearly evident at $\sim 0.8 \mathrm{~J} / \mathrm{m}^{2}$. The dashed curves represent predictions from the transport - reaction model for the 1.5, 3, and $10 \mathrm{wt} \% \mathrm{H}_{2} \mathrm{O}_{2}$ environments. (b) Corrosion of MSSQ in $\mathrm{H}_{2} \mathrm{O}_{2}+\mathrm{NaOH}$ solutions allows cracking to extend to extremely low values of $\mathrm{G}$.

Preliminary studies have addressed the effect of moisture and water on the rate of crack growth orthogonal to lithographically patterned arrays of copper and MSSQ lines as shown in Figure 5 [22]. It is clearly apparent that with increasing activity of water in the test environment, crack growth rates increase significantly and the threshold value of $G$ shifts to much lower values. Note the absence of a well defined reaction region and that the slope of the threshold region is similar for each curve. The debond path for these structures was determined by detailed characterization of the fractured 
surfaces with X-ray photoelectron spectroscopy (XPS), atomic force microscopy (AFM) and high-resolution scanning electron microscopy (SEM), Figure 5 (b \& c).

(a)
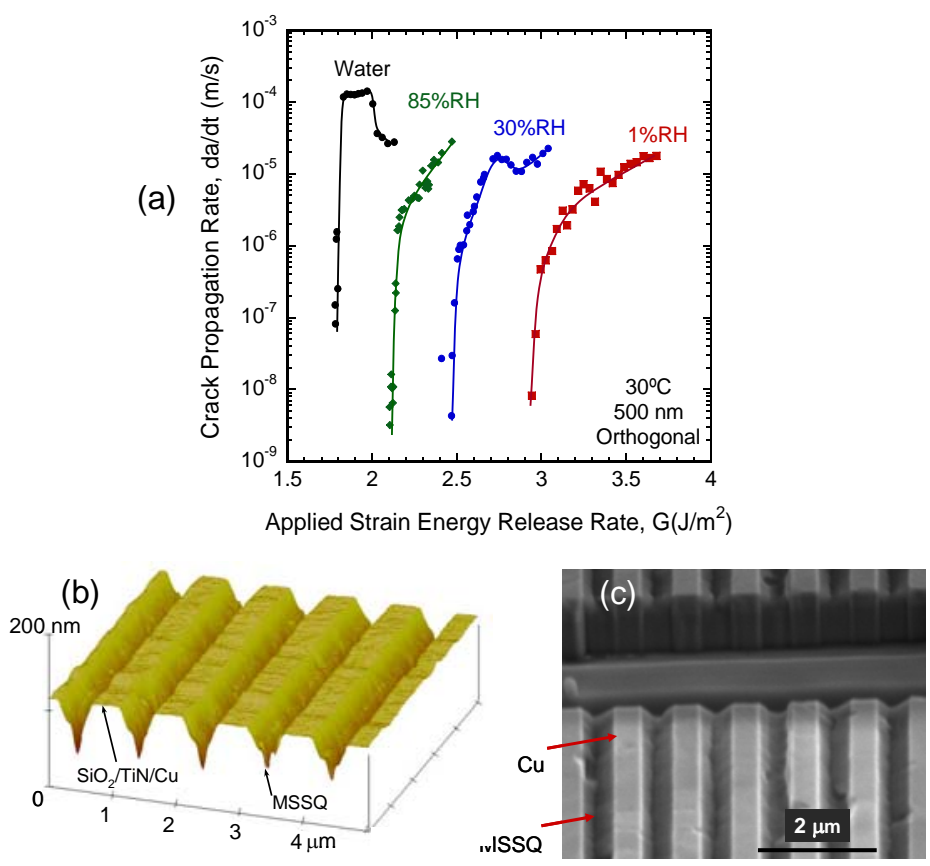

Figure 5: (a) Effect of moisture on the accelerated cracking of 500nm width lines and cracking orthogonal to the features. (b) AFM and SEM of fractured surfaces. The debond location was determined using high resolution XPS .

\subsection{Multi-Scale Modeling Activities}

The intent of our research program is not only to identify and characterize salient mechanisms responsible for fracture and subcritical crack growth, but also to develop mechanistic models describing such processes. These activities are summarized below to motivate the modeling activities proposed in the continuation program.

Length scales are important in the treatment of interface debonding problems in layered structures. We have developed a robust multi-scale simulation capability to study the effects of selected interface cohesive parameters, adjacent ductile layers, and selected loading parameters on the mechanics of interfacial fracture. In addition, we have the ability to explore the effect of initial stress state in either ductile layers, or elastic barrier layers on the interface debonding energies.

Work in the present program has concentrated on understanding the effects of residual film stress on the local plasticity that occurs during debonding. Such residual stresses may arise from thermal expansion mismatch, epitaxial strains, or other growth 
stresses produced during processing. They are often very large, in the case of ductile metal layers at the yield stress for the material. We have systematically explored the effects of residual stresses in both the ductile layer and adjacent elastic layer $[14,15]$. We demonstrated that residual stresses may have a significant effect on the extent of local plasticity during debonding and the resulting value of $G_{c}$. The effect of the sign of the residual stress and the applied loading mode mixity was also examined. Surprisingly, compressive residual stresses in the thin films were found to elevate plasticity in the ductile layer, rather than tensile stresses that intuitively might be expected to enhance plastic flow in the presence of the tensile crack tip stress fields.

Based on the above surprising results, we initiated a combined experimental and multiscale modeling study of the fracture energy of a $\mathrm{TaN} / \mathrm{SiO}_{2}$ barrier layer interface adjacent to a ductile $\mathrm{Cu}$ film with varying levels of residual stress [16]. Results are shown in Figure 6. The thin-film stack was thermally cycled in order to systematically vary the residual stress of the $\mathrm{Cu}$ film. X-ray diffraction techniques were used to characterize the resulting residual stress in the $\mathrm{Cu}$ layer by measuring the strain accommodated in the interplanar spacing of select $\mathrm{Cu}$ crystal planes. The fracture energy of the $\mathrm{TaN} / \mathrm{SiO}_{2}$ interface increased by $50 \%$ for structures containing a $\mathrm{Cu}$ film in compression compared to similar structures containing a $\mathrm{Cu}$ film in tension. Trends in $\mathrm{G}_{\mathrm{c}}$ from multi-scale simulations using relevant interface and material properties were able to accurately predict the experimentally observed behavior (Figure 6). The effect of residual stress on interfacial adhesion is rationalized in terms of the onset of yielding within the $\mathrm{Cu}$ film, which affects the contribution from plastic energy dissipation to the total interface fracture energy. 


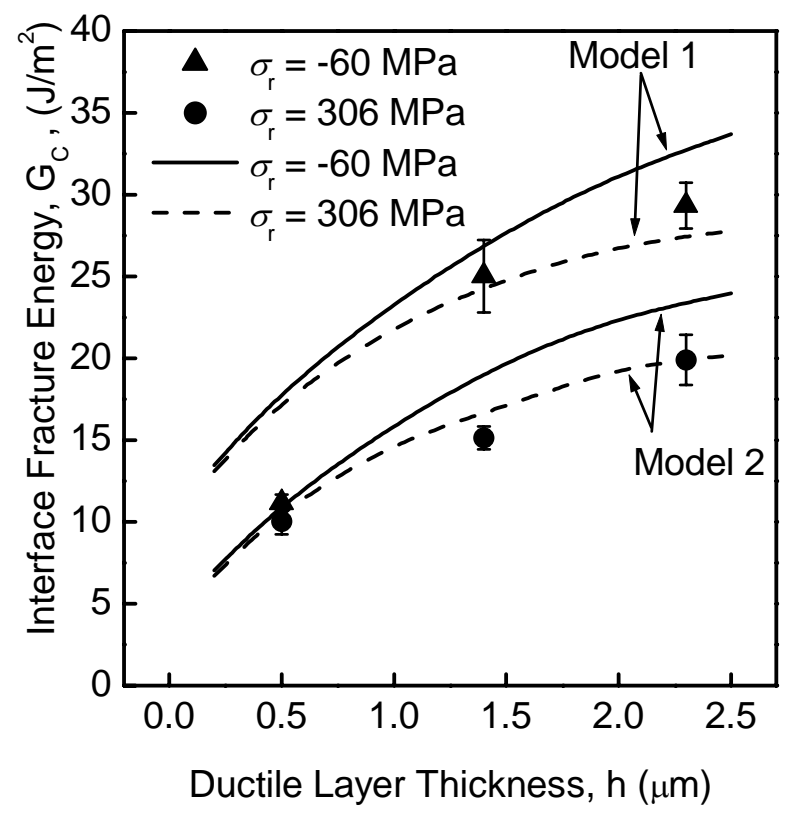

Figure 6: Measurements of $\mathrm{G}_{\mathrm{C}}$ for the $\mathrm{TaN} / \mathrm{SiO}_{2}$ interface closely match the values and trends predicted using multi-scale simulations. Model 1 and Model 2 provide a reasonable upper and lower bound for the relevant $\mathrm{Cu}$ yield properties and $\mathrm{TaN} / \mathrm{SiO}_{2}$ interface cohesive zone conditions [16].

\subsection{Subcritical Crack Growth in Hydroxyapatite Bone Substitute Materials}

In our DOE program, we have also been interested in environmentally assisted cracking in other brittle materials. Vicki Jew in her PhD program has been studying the subcritical crack growth properties in selected hydroxyapatite bone substitute materials using a fracture mechanics approach. Subcritical crack growth, comprising both cyclic fatigue crack growth and stress corrosion cracking, can lead to much lower load-bearing ability in these important new materials used for bone fracture fixation. Her research has shown for the first time that these materials are susceptible to crack growth under cyclic fatigue as well as stress corrosion conditions. In her work she has demonstrated that cyclic fatigue behavior is due to environmental effects only; no mechanically-induced damage mechanisms contribute to crack growth.

Stress corrosion cracking was examined for a range of environmental conditions (Figure 3). We believe this is the first evidence ever presented of stress corrosion behavior in calcium phosphate cements [23]. Changes in $\mathrm{pH}$ of the surrounding environment have surprisingly little effect on stress corrosion cracking, despite the 
increased solubility of $\mathrm{HA}$ in acidic environments. Compared to water at ambient temperature $\left(22^{\circ} \mathrm{C}\right)$, water at elevated temperature $\left(50^{\circ} \mathrm{C}\right)$ alters stress corrosion cracking behavior only for crack-growth velocities below $10^{-7} \mathrm{~m} / \mathrm{s}$. Using reaction rate theory, activation volumes and activation energies for the bond rupture process were calculated. Activation volumes were found to be about an order of magnitude greater than for soda lime and silicate glasses. Activation energies were also found to be much higher than for these glasses, by almost an order of magnitude. These high values may be explained by the more ionic nature of the bonds found in hydroxyapatite compared to glasses or polymers. Hydroxyapatite also has a more complex structure, and forms a number of different chemical species at the apatite-water interface.

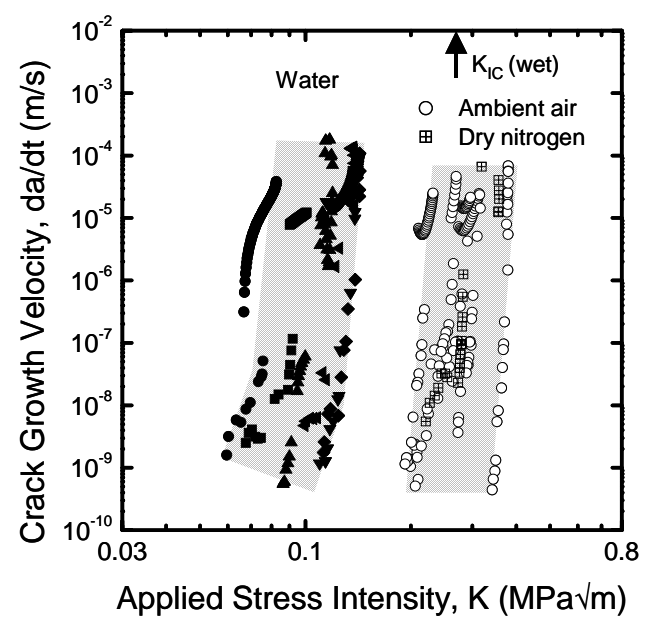

(a)

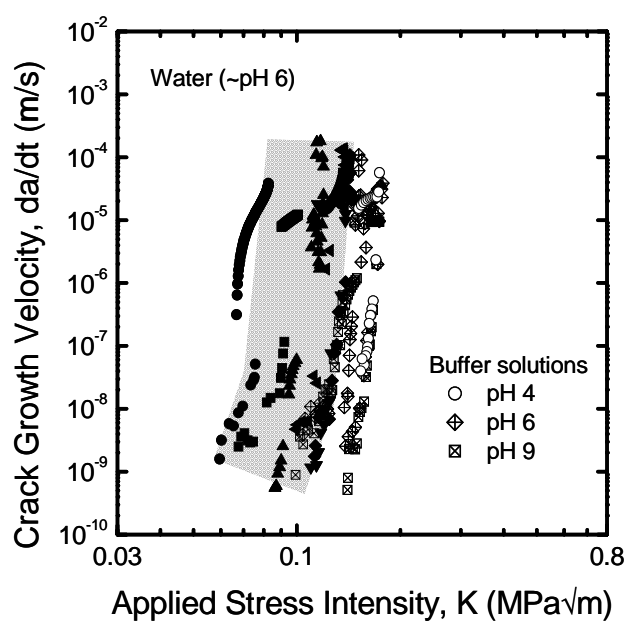

(b)

Figure 7: Crack growth velocity as a function of applied stress intensity for a calcium carbonate synthetic bone substitute material in room temperature water compared to a) air, b) buffer solutions of $\mathrm{pH} 4,6$, and 9 .

\subsection{Fracture and Fatigue Crack-Growth in Silicon MEMS Structures}

Single crystal silicon is often used as either the substrate material or the structural material in MEMS devices. Many of these devices, such as automotive sensors, are intended for use over long durations in hostile environments where they may be exposed to significant fatigue loading and potentially corrosive species. As a result, there is an increasing need for understanding the mechanical behavior of silicon during such long term exposure, particularly with respect to potential subcritical crack-growth processes associated with mechanical fatigue crack growth or moisture-assisted stress corrosion cracking. Indeed, the existence of fatigue damage in MEMS structures has been 
reported in several recent studies [24, 25], although the process does not appear to be related to fatigue crack growth but rather to the initiation of fatigue damage [5].

Such fatigue behavior is not surprising in single crystal brittle solids which, due to the low mobility of dislocations and resulting lack of plasticity, do not typically exhibit mechanical cyclic fatigue crack growth similar to crystalline metals and other ductile materials. In brittle materials like glasses [3] and single crystal ceramics [26], subcritical crack propagation is rarely accelerated by mechanical fatigue loading but results from an environmentally-assisted stress corrosion crack-growth process [27]. Surprisingly, however, the existence of a moisture-assisted subcritical crack-growth process has not been unambiguously established in crystalline silicon [28]. In addition, the role of fatigue crack growth in the reported fatigue damage process is also unresolved [5].

The objective of the present study was therefore to carefully investigate the existence of a stress-corrosion cracking and fatigue crack-growth processes in silicon in moist air using novel micro-machined specimens [8]. The advantage of the micromachined specimen was, firstly, lithographic definition of the fracture mechanics geometry which provides a very stable crack growth configuration, secondly, the precise positioning of an initial notch and narrow side groove ( $8 \mu \mathrm{m}$ wide) to further stabilize the crack plane, and finally, incorporation of an electrical sensor or crack length gauge to facilitate in situ high resolution crack length measurements $( \pm 0.5 \mu \mathrm{m}$, with averaging), which allows more accurate measurement of crack-growth rates to very low values (< $\left.10^{-10} \mathrm{~m} / \mathrm{s}\right)$.

Crack length and loads were carefully monitored throughout fatigue and stresscorrosion tests in order to distinguish between environmentally assisted crack growth (stress corrosion) and mechanically induced fatigue-crack growth. Results revealed similar step-like crack extension versus time for the cyclic and monotonic tests. The fatigue crack-growth curve extracted from the crack extension data exhibited a nearly vertical slope with no evidence of accelerated crack-growth rates (Figure 8). We believe these subcritical crack-growth studies on silicon to be the most careful to date, representing unprecedented control on both applied loading and crack length detection. They are important in determining the role of crack growth, as opposed to initiation phenomena, in the fatigue lives of MEMS structures. Fracture surfaces for the monotonic and cyclic tests were similar, further suggesting that a true mechanical fatigue crack-growth mechanism did not occur. Explanations for the observed lack of fatigue 
crack growth are presented and discussed with respect to reported stress-life behavior in ref. 8.

The same specimen geometry was employed to undertake unique measurements of multiple microsecond-duration arrest periods during the propagation of high speed (> $1 \mathrm{~km} / \mathrm{s}$ ) cracks in micro-machined single crystal silicon specimens [29]. These events were recorded electronically and in physical features remaining on the fracture plane. Using time-of-flight calculations, we have determined that these arrest patterns are due to the interference of boundary-reflected stress waves with the propagating crack tip.

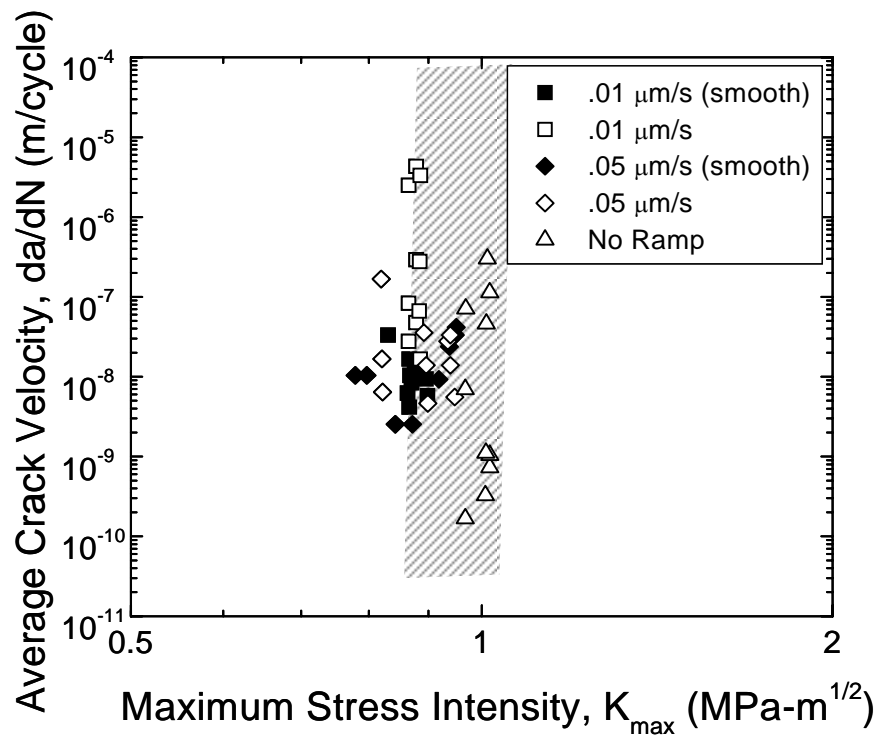

Figure 8: Fatigue crack-growth data, da/dt vs. $K_{\max }$, measured in single crystal silicon MEMS specimens are compared for cyclic and static fatigue tests. Shaded band shows previously reported static fatigue test results in $50 \%$ relative humidity. 


\section{PERSONNEL AND STUDENTS SUPPORTED ON CURRENT PROGRAM}

Four Ph.D. students and one M.Sc. students supported by our DOE program have graduated during the course of the current DOE program. Overall, eight Ph.D. and five M.S. students have graduated with support from our DOE program since the first program in 1995. Their names and theses titles together with current positions are listed below. The progress described in the section above reflects the efforts of four Ph.D. students and one M.Sc. student all supported by our DOE program. Three of the Ph.D. students and the M.Sc. student have recently graduated. Two additional Ph.D. students have joined the program.

\section{Principal Investigator:}

Reinhold H. Dauskardt, Professor

\section{Currently Supported Graduate Students:}

David Gage (Ph.D. expected: )

Markus Ong (partial support, Ph.D. expected: )

Mary Ann Shuller (partial support, Ph.D. expected: )

\section{Awards and Honors}

Reinhold H. Dauskardt

Alexander von Humboldt Research Award in 2002

ASM International Silver Medal in 2003.

Eric Guyer (graduate student)

Electrochemical Society, Dr. Daniel Cubicciotti Award (2004)

Northern California Chapter of the American Vacuum Society, $1^{\text {st }}$ Place Poster Award (2004)

Materials Research Society, Outstanding Poster Award (2004)

Materials Research Society, Silver Graduate Student Award (2003)

\section{Graduated Students on DOE Program:}

Eric Guyer (Ph.D. )

Thesis: The Effects of Aqueous Solution Chemistry on the Fracture of Nanoporous Thin-Films

Currently: Postdoctoral fellow, Materials Science and Engineering, Stanford University. 
Victoria Jew (Ph.D. )

Thesis: Mechanical and Fracture Behavior of Synthetic Bone Materials

Currently: Technical Consultant, Livermore, CA.

Sven Strohband (Ph.D. )

Thesis: Multi-Scale Simulations of Interface Separation in Thin-Film Structures

Currently: Senior Engineer, Electronics Research Laboratories, Volkswagen of America.

Marc Taub (Ph.D. )

Thesis: A Mechanics Approach to the Study of Pressure Sensitive Adhesives and Human Skin

Currently: Senior Engineer, TheraSense Corporation, Alameda, CA.

Emily Renuart (M.S. )

Thesis: Fatigue Crack Growth in Micro-Machined Single Crystal Silicon

Currently: Instructor, Science Museum, San Jose, CA.

Alissa M. Fitzgerald (Co-Advised with Prof. T. Kenny, Graduated Ph.D.: J)

Thesis: Crack Growth Phenomena if Micro-Machined Single Crystal Silicon and Design Implications for MEMS

Currently: Manager of Process Engineering, Sensant Corporation, San Leandro, CA.

Mit Shah (Graduated M.Sc., )

Thesis: High-Resolution, Compliance-Based Subcritical Crack-Growth Measurement Techniques for Layered Structures

Currently: Technical Consultant, San Jose, CA.

Michael Lane (Graduated Ph.D.: )

Thesis: Adhesion in Multi-Layer Thin Film Structures: Chemistry, Morphology, Plasticity and environmental Effects

Currently: Research Staff Member, Mat. Sci. and Interconnect Reliability, IBM T. J.

Watson Research Center, Yorktown Hts., NY

Ajay Bhatnagar (Graduated Ph.D.: )

Thesis: Subcritical Crack-Growth Behavior in Advanced Silicon Nitride Ceramics

Currently: Materials Engineer, Applied Materials Corporation, Santa Clara, CA.

Ashwini K Sharma (Graduated M.Sc., )

Thesis: Automated Subcritical Crack-Growth Measurement Techniques for Elevated Temperature Testing

Currently: Technical Consultant, San Jose, CA.

Keith S. Yi (Graduated Ph.D.: )

Thesis: Fatigue Crack-Growth Behavior of Materials in Viscous Fluid Environments

Currently: (Part-Time) Post Doctoral Fellow, Department of Materials Science and Engineering, Stanford University, and Senior Staff Engineer, TRW Inc., Sunnyvale, CA.

Sara Dill (Graduated M.Sc., )

Thesis: Subcritical Crack-Growth Behavior in Borosilicate Glasses: Evidence of a Mechanical Fatigue Effect 
Currently: Energy Consultant, Boston, MA.

Christopher Burpee (Graduated M.Sc., )

Thesis: Subcritical Crack-Growth Behavior in Glasses for Optical Fiber Applications Currently: Senior Engineer, Pacific Bell Telecommunication, CA.

\section{COLLABORATIONS INITIATED}

We have also developed a range of collaborative efforts which include Profs. T. Kenny and K. J. Cho in the Mechanical Engineering Department at Stanford, Prof. H. Gao at the Max Planck Institute in Stuttgart, Germany, Dr. Patrick Klein of the Structural and Thermomechanical Modeling Group at Sandia National Laboratory, Prof. W. D. Nix at Stanford University, Prof. J. W. Hutchinson at Harvard University, Prof. P. Ho at UT Austin, Drs. B. Sun and J. Xu at INTEL, Drs. N. Krishna and K. McWilliams at Applied Materials, Drs. R. Miller and W. Volksen at IBM Almaden Research Center, Dr. Matthias Patz at the Tsukuba Research Laboratory, JSR Corporation, Japan, and Dr. Iacopi Francesca at IMEC, Belgium. These collaborative efforts involve a free exchange of materials and information and have resulted in a number of research publications listed.

\section{PUBLICATIONS FROM DOE PROGRAM}

\section{Current Program:}

1. F.lacopi, Y.Travaly, B.Eyckens, C.Waldfried, T.Abell, E.P.Guyer, D.M.Gage, R.H.Dauskardt, T.Sajavaara, K.Houthoofd, P.Grobet, P.Jacobs, K.Maex, "Shortranged structural rearrangement and enhancement of mechanical properties of organosilicate glasses induced by UltraViolet radiation," Journal of Applied Physics, 99, 2006.

2. E. P. Guyer, M. Patz, and R. H. Dauskardt, "Fracture of Nanoporous Methyl Silsesquioxane Thin-Film Glasses," Journal of Materials Research, 21 [4], 2006.

3. D. M. Gage, K. Kim, C. S. Litteken, and R. H. Dauskardt, "The Role of Friction and Loading Parameters on Four-Point Bend Adhesion Measurements," Journal of Materials Research, 2005. In review.

4. E. P. Guyer and R. H. Dauskardt, "Effect of Solution pH on the Accelerated Cracking of Nanoporous Thin-Films Glasses," Journal of Materials Research, 20 [3], $680-687,2005$.

5. E. P. Guyer and R. H. Dauskardt, "Accelerated Debonding and Cracking in ThinFilm Structures: Chemical Reaction Rate and Loading Effects," proceedings of the $\underline{11}^{\text {th }}$ International Conference of Fracture, Turin, Italy, March, 2005. 
6. E. P. Guyer, C. Litteken, D. Maidenberg, and R. H. Dauskardt, "Reliability of Thin-Film Structures for Device Technologies: Adhesion, New Materials and Length Scale Challenges," Interfaces In Electronic Materials, Electrochemical Society, 2004. In press.

7. S. Stroband and R. H. Dauskardt, "Effect of Barrier Layer Properties on Adhesion in Thin-Film Structures," International Journal of Fracture, 2004. In review.

8. C. S. Litteken, S. Stroband, and R. H. Dauskardt, "Residual Stress Effects on Plastic Deformation and Interfacial Fracture in Thin-Film Structures," Acta Materialia, 53 [7], 1955-1961, 2005.

9. A. Lee, C.S. Litteken, R. H. Dauskardt and W.D. Nix, "Comparison of the Telephone Cord Delamination Method for Measuring Interfacial Adhesion with the Four-Point Bending Method," Acta Materialia, 53, 609-616, 2005.

10. E. P. Guyer and R. H. Dauskardt, "Effect of Aqueous Solution Chemistry on the Accelerated Cracking of Lithographically Patterned Arrays of Copper and Nanoporous Thin-Films," MRS Symposium Proceedings Materials Research Society, Warrendale, PA. 2004.

11. E. P. Guyer and R. H. Dauskardt, "Accelerated Crack Growth of Nanoporous Low-k Glasses in Aqueous Solutions," proceedings of the Annual Meeting of the Electrochemical Society, Hawaii, 2004.

12. E. P. Guyer and R. H. Dauskardt, "Electrical Resistance Technique to Measure Crack Length in Fracture Mechanics Specimens Containing Thin-Film Structures," Journal of Materials Research, 19 [11], 3139-3144, 2004.

13. E. Renuart, A.M. Fitzgerald, T.W. Kenny, and R.H. Dauskardt, "Fatigue Crack Growth in Micro-Machined Single Crystal Silicon Specimens," Journal of Materials Research, 19 [9] 2635-2640, 2004.

14. E. P. Guyer and R. H. Dauskardt, "Fracture of Nanoporous Thin-Film Glasses," Nature Materials, published online, 7 December 2003. In print: 3, 53-57, 2004.

15. E. P. Guyer and R. H. Dauskardt, Accelerated Crack Growth of Nanoporous Low-k Glasses in CMP Slurry Environments, IEEE International Interconnect Technology Conference Proceedings, to be published in June 2004.

16. E. P. Guyer, R. H. Dauskardt, Effect of CMP Slurry Environments on Subcritical Crack Growth in Ultra Low-k Dielectric Materials, IEEE International Interconnect Technology Conference Proceedings, June 2003.

17. S. Stroband and R. H. Dauskardt, "Interface Separation in Residually Stressed Thin-Film Structures," Interface Science special issue on "Mechanics of Interfaces" 11 (3), 309-317, 2003.

18. J. P. Morgan and R. H. Dauskardt, "Notch Strength Insensitivity of Self-Setting Hydroxyapatite Bone Cements," Journal of Materials Science: Materials in Medicine, 14, $647-653,2003$.

19. A.M. Fitzgerald, R.H. Dauskardt, and T.W. Kenny, "Stress Wave Interference Effects during Fracture of Silicon Micromachined Specimens," Journal of Experimental Mechanics, 43 [3] 317 - 322, 2003.

20. S. Stroband and R. H. Dauskardt, "Multi-Scale Simulations Of Interfacial Fracture Of Nanoscale Thin-Film Structures: Effect Of Length Scales and Residual 
Stresses," MRS Symposium Proceedings Materials Research Society, Warrendale, PA. 2003.

21. E. P. Guyer and R. H. Dauskardt, "Effect of CMP Slurry Environments on Subcritical Crack Growth in Ultra Low-k Dielectric Materials," Proceedings of the International Interconnects and Technology Conference, San Francisco, CA, 2003.

Previous DOE Program:

22. A.M. Fitzgerald, R.S. Iyer, R.H. Dauskardt, and T.W. Kenny, "Subcritical Crack Growth in Single Crystal Silicon using Micro-Machined Specimens," Journal of Materials Research, 17 [3], 683-692, 2002.

23. M. W. Lane, J. M. Snodgrass, and R. H. Dauskardt, "Environmental Effects on Interfacial Adhesion," Microelectronics Reliability, 41 [9-10], 1615-1624, 2001.

24. E. D. Renuart, A. M. Fitzgerald, T. W. Kenny, and R. H. Dauskardt, "Fatigue Processes in Silicon MEMS Devices," in the Proceedings of the Spring MRS Conference, San Francisco, March 18, 2001.

25. A. M. Fitzgerald, R. H. Dauskardt, and T. W. Kenny, "Fracture Toughness and Crack Growth Phenomena of Plasma-Etched Single Crystal Silicon," Sensors and Actuators: A, 83, 194-199, 2000.

26. M. Lane, A. Vainchtein, H. Gao and and R. H. Dauskardt, "Plasticity Contributions to Interface Adhesion in Thin-Film Interconnect structures," Journal of Materials Research, 15 [12], 2758-2769, 2000.

27. M. Lane, N. Krishna, I. Hashim, and R. H. Dauskardt, "Adhesion and Reliability of Copper Interconnects with Ta and TaN Barrier Layers," Journal of Materials Research, 15 [1] 203-211, 2000.

28. A. Bhatnagar, M. J. Hoffmann and R.H. Dauskardt, "Fracture and Subcritical Crack-Growth Behavior of Y-Si-Al-O-N Glasses and $\mathrm{Si}_{3} \mathrm{~N}_{4}$ Ceramics," Journal of the American Ceramics Society, 83 [3] 585-596, 2000.

29. V. Jew, J. P. Morgan and R. H. Dauskardt, "Strength, Toughness and Fatigue of an Apatite Cement," in Orthopaedic/Dental Biomaterials, Proceedings of the Fall MRS Meeting, Boston, 2000.

30. M. Lane, N. Krishna, I. Hashim, and R. H. Dauskardt, "Effect of Nitrogen on Adhesion of the $\mathrm{Ta} / \mathrm{SiO}_{2}$ Interface," in Materials Reliability in Microelectronics IX, Proceedings of the Spring MRS Meeting, San Francisco, 1999.

31. M. Lane, Qing Ma, H. Fujimoto, N. Krishna, and R. H. Dauskardt, "Subcritical Debonding of Multilayer Interconnect Structures: Temperature and Humidity Effects," in Materials Reliability in Microelectronics IX, Proceedings of the Spring MRS Meeting, San Francisco, 1999.

32. A.M. Fitzgerald, R.H. Dauskardt, and T.W. Kenny, "Fracture Toughness of Plasma-Etched Single Crystal Silicon and Implications for MEMS Design," in Symposium on Microelectromechanical Systems, Transducers $99010^{\text {th }}$ 
International Conference on Solid-State Sensors and Actuators, Sendai, Japan, 1999.

33. F. G. Haubensak, A. Bhatnagar, and R.H. Dauskardt, "Subcritical Growth of Microstructurally Small Cracks in Silicon Nitride Ceramics," in Small Fatigue Cracks: Mechanics, Mechanisms and Applications, Editors R.K.S. Ravichandran, R.O. Ritchie, and Y. Murakami, Elsevier, pp. 271-282, 1999.

34. J. Mroz, R. H. Dauskardt and U. Schleinkofer, "New Adhesion Measurement Technique for Coated Cutting Tool Materials," International Journal of Refractory Metals and Hard Materials, 16 395-402, 1998.

35. K. S. Yi, B. N. Cox and R. H. Dauskardt, "Subcritical Crack-Growth Behavior in Materials Under Cyclic Loads: Effect of Hydrodynamic Pressure Created by Viscous Environments," Journal of the Mechanics and Physics of Solids, 47 [9] 1843-1871, 1998.

36. A.M. Fitzgerald, R. Suryanarayanan lyer, R.H. Dauskardt, and T.W. Kenny, "Fracture and Sub-Critical Crack Growth Behavior of Micromachined Single Crystal Silicon Structures," in Symposium on Microelectromechanical Systems, 1998 ASME International Mechanical Engineering Congress \& Exopsition, Nov. 15-20, 1998, Anaheim, California.

37. R. H. Dauskardt, M. Lane, Q. Ma, and N. Krishna, "Adhesion and Debonding of Multi-Layer Thin Film Structures," Engineering Fracture Mechanics, 61 [1] 141162, 1998.

38. K. S. Yi, S. J. Dill and R. H. Dauskardt, "Subcritical Crack-Growth Behavior in Glasses and Ceramics: Effect of Hydrodynamic Pressures in Aqueous Environments," Acta Metallurgica et Materialia, 45, 2671 (1997).

39. S. J. Dill, S. J. Bennison and R. H. Dauskardt, "Subcritical Crack-Growth Behavior of Borosilicate Glass under Cyclic Loads: Evidence of a Mechanical Fatigue Effect," Journal of the American Ceramics Society, 80 [3] 773-76 (1997).

\section{RELATED RECENT PRESENTATIONS AND INVITED LECTURES}

1. July 2005, "Adhesion and Mechanical Reliability of Interconnect Structures: New Material and Processing Challenges," invited presentation at the Workshop on Stress Induced Phenomena, Tokyo Institute of Technology, Tokyo, Japan.

2. July 2005, "Mechanical Behavior of Thin-Film Structures for Emerging Technologies: Front and Back End Device Structures," invited presentation at the International Conference of Materials for Advanced Technologies, ICMAT 2005, Singapore.

3. April 2005, "Fracture in Thin-Film Structures for Device Technologies: New Material and Length Scale Challenges," invited presentation at the Annual Meeting of the American Ceramics Society, Baltimore, MD.

4. March 2005, "Fracture and Mechanical Behavior in Thin-Film Interconnect Structures: Challenges for Next Technology Nodes," invited presentation at the 2005 Spring Meeting of the Materials Research Society, San Francisco, CA. 
5. March 2005, "Accelerated Debonding and Cracking in Thin-Film Structures: Chemical Reaction Rate and Loading Effects," invited presentation $11^{\text {th }}$ International Fracture Conference, Turin, Italy.

6. March 2005, "Mechanisms of Fatigue damage and Evolution in Zr-Based Bulk Metallic Glasses," invited presentation $11^{\text {th }}$ International Fracture Conference, Turin, Italy.

7. March 2005, "Fracture in Thin-Film Structures for Emerging Device Technologies," invited presentation $11^{\text {th }}$ International Fracture Conference, Turin, Italy.

8. March 2005, "Adhesion in Thin-Film Structures for Emerging Technologies," invited presentation in the Division of Polymeric Materials, $229^{\text {th }}$ Annual Meeting of the American Chemical Society, San Diego, CA.

9. February 2005, "Cohesive and Adhesive Fracture in Complex Device Structures," invited presentation in the Symposium of Mechanical Behavior of Thin Films and Small Scale Structures, $134^{\text {th }}$ Annual TMS Conference, San Francisco, CA.

10. November 2004, "Fracture in Complex Device Structures" invited colloquium, Department of Materials Science and Engineering, UC Berkeley, Berkeley, CA.

11. September 2004, "Mechanical Behavior of Patterned Device Structures," NanoInterface Workshop, University of Tokyo, Tokyo, Japan.

12. August 2004, "Adhesion and Mechanical Reliability of Thin-Film Devices: New Material and Length Scale Challenges," invited lecture at the Gordon Research Conference on Adhesion, Tilton, $\mathrm{NH}$.

13. June 2004, "Fracture in CU/Low k Damascene Line Structures: Design for Toughness and Resistance to Cracking in Aqueous CMP Solutions," invited presentation at the 7th International Workshop on Stress-Induced Phenomena in Metallization, Austin, TX.

14. April 2004, "Effect of Chemically Active Environments on Subcritical CrackGrowth in Low-k Dielectric Materials" (with E. P. Guyer) at the 2004 Spring Meeting of the Materials Research Society, San Francisco, CA.

15. April 2004, "Fracture of Calcium Phosphate Cement with Second Phase Organic Additions" (with V. Jew) at the 2004 Spring Meeting of the Materials Research Society, San Francisco, CA.

16. March 2004, "Mechanical and Fracture Behavior of Thin-Film Structures for Device Technologies," Symposium on Internal Stresses and Thermomechanical Behavior of Multi Component Systems, Annual TMS Meeting, Charlotte, NC.

17. February 2004, "Effect of Complex CMP Aqueous Environments on Accelerated Cracking and Reliability of Ultra Low-k Dielectric Materials," ICMI - American Vacuum Society, Santa Clara, CA.

18. February 2004, "Fracture in Thin-Film Device Structures," invited colloquium, Department of Materials Science and Engineering, Northwestern, Evanston, IL.

19. February 2004, "Fracture in Thin-Film Device Structures," invited Materials Research Lectures, California Institute of Technology, Pasadena, CA. 
20. November 2003, "Adhesion and Reliability of Thin-Film Structures for Device Technologies: New Material and Length Scale Challenges," invited colloquium, Department of Mechanical Engineering, UCSB, Santa Barbara, CA.

21. October 2003, "Adhesion and Mechanical Reliability of Thin-Film Structures," Annual Meeting of the Electrochemical Society, Orlando, FL.

22. June 2003, "Adhesion and Reliability in Device Structures," invited presentation at the ASME Summer Meeting, Phoenix, AZ.

23. June 2003, "Effect of CMP Slurry Environments on Subcritical Crack Growth in Ultra Low-k Dielectric Materials, (with E. P. Guyer), IEEE International Interconnect Technology Conference, Burlingame, CA.

24. April 2003, "Multi-Scale Simulations of Interfacial Fracture of Nanoscale ThinFilm Structures: Effect of Length Scales and Residual Stresses" (with S. Stroband) at the 2003 Spring Meeting of the Materials Research Society, San Francisco, CA.

25. April 2003, "Effect of Environment and Organic Phases on Stress Corrosion Cracking in Calcium Phosphate Cement" (with V. Jew) at the 2003 Spring Meeting of the Materials Research Society, San Francisco, CA.

26. April 2003, "Effect of Chemically Active Environments on Subcritical Crack Growth in Low-k Dielectric Materials" (with E. P. Guyer) at the 2003 Spring Meeting of the Materials Research Society, San Francisco, CA.

27. March 2003, "Adhesion and Reliability in Thin-Film Structures: New Material and Length Scale Challenges," invited presentation at the TMS Annual Meeting, San Diego, CA.

28. September 2002, "Adhesion and Reliability in Thin-Film Structures Containing $\mathrm{Cu}$ and Low-k Materials: Experiments and Multi-Scale Simulations," invited presentation at the International Conference on Solid State Devices and Materials, Japan Society of Applied Physics, Nagoya, Japan.

29. March 2002, "Adhesion and Fracture in Thin-Film Device Structures: Experiments and Multi-Scale Simulations," invited presentation, Spring Meeting of the Condensed Matter Division of the German Physical Society, Regensburg, Germany.

30. August 2001, "Mechanics and Fracture in Thin Film Device Structures," invited lecture at the Gordon Research Conference on Solid State Studies in Ceramics, Meriden, $\mathrm{NH}$.

31. July 2001, "Fracture and Reliability of Thin-Film Device Structures for advanced Technologies," invited presentation, International Conference of Materials for Advanced Technologies, Materials Research Society (Singapore), Singapore.

32. June 2001, "Fatigue and Fracture in Thin-Film Structures," invited presentation, 2001 Mechanics and Materials Summer Conference, ASME, ASCE and SES, San Diego, CA.

33. June 2001, "Adhesion and Mechanical Reliability of New Low-k Materials for Interconnect Structures," Keynote Lecture, 2001 Mechanics and Materials Summer Conference, ASME, ASCE and SES, San Diego, CA.

34. March 2001, "Mechanisms of Environmentally-Assisted Debonding in Thin-Film Structures," invited presentation in the Symposium on Fundamental Studies of Corrosion 
and Oxidation at the 2001 Spring Meeting of the Materials Research Society, San Francisco, CA.

35. March 2001, "Adhesion and Mechanical Behavior of Barriers in Interconnect Structures," invited presentation in the Symposium on Materials, Technology, and Reliability for Advanced Interconnects and Low-k Dielectrics at the 2001 Spring Meeting of the Materials Research Society, San Francisco, CA.

36. March 2001, "Mechanisms of Environmentally-Assisted Debonding in Thin-Film Structures," invited presentation in the Symposium on Fundamental Studies of Corrosion and Oxidation at the 2001 Spring Meeting of the Materials Research Society, San Francisco, CA. 


\section{REFERENCES}

1. F. G. Haubensak, A. Bhatnagar, and R.H. Dauskardt, "Subcritical Growth of Microstructurally Small Cracks in Silicon Nitride Ceramics," in Small Fatigue Cracks: Mechanics, Mechanisms and Applications, Editors R.K.S. Ravichandran, R.O. Ritchie, and Y. Murakami, Elsevier, pp. 271-282, 1999.

2. A. Bhatnagar, M. J. Hoffmann and R.H. Dauskardt, "Fracture and Subcritical Crack-Growth Behavior of Y-Si-Al-O-N Glasses and $\mathrm{Si}_{3} \mathrm{~N}_{4}$ Ceramics," Journal of the American Ceramics Society, 83 [3] 585-596, 2000.

3. S. J. Dill, S. J. Bennison and R. H. Dauskardt, "Subcritical Crack-Growth Behavior of Borosilicate Glass under Cyclic Loads: Evidence of a Mechanical Fatigue Effect," Journal of the American Ceramics Society, 80 [3] 773-76, 1997.

4. R. H. Dauskardt, M. Lane, Q. Ma, and N. Krishna, "Adhesion and Debonding of Multi-Layer Thin Film Structures," Engineering Fracture Mechanics, 61 [1] 141162, 1998.

5. E. D. Renuart, A. M. Fitzgerald, T. W. Kenny, and R. H. Dauskardt, "Fatigue Processes in Silicon MEMS Devices," in the Proceedings of the Spring MRS Conference, San Francisco, March 18, 2001.

6. A.M. Fitzgerald, R.H. Dauskardt, and T.W. Kenny, "Fracture Toughness of Plasma-Etched Single Crystal Silicon and Implications for MEMS Design," in Symposium on Microelectromechanical Systems, Transducers $9910^{\text {th }}$ International Conference on Solid-State Sensors and Actuators, Sendai, Japan, 1999.

7. A.M. Fitzgerald, R.S. Iyer, R.H. Dauskardt, and T.W. Kenny, "Subcritical Crack Growth in Single Crystal Silicon using Micro-Machined Specimens," Journal of Materials Research, 17 [3], 683-692, 2002.

8. E. Renuart, A.M. Fitzgerald, T.W. Kenny, and R.H. Dauskardt, "Fatigue Crack Growth in Micro-Machined Single Crystal Silicon Specimens," Journal of Materials Research, 19 [9] 2635-2640, 2004.

9. M. Lane, R. H. Dauskardt, R. Ware, Q. Ma and H. Fujimoto, "Progressive Debonding of Multi-Layer Interconnect Structures," in Materials Reliability in Microelectronics VII, Proceedings of MRS Annual Meeting, San Francisco, CA, 21-26, 1997.

10. M. Lane, Qing Ma, H. Fujimoto, N. Krishna, and R. H. Dauskardt, "Subcritical Debonding of Multilayer Interconnect Structures: Temperature and Humidity Effects," in Materials Reliability in Microelectronics IX, Proceedings of the Spring MRS Meeting, San Francisco, 1999.

11. E. P. Guyer and R. H. Dauskardt, "Electrical Resistance Technique to Measure Crack Length in Fracture Mechanics Specimens Containing Thin-Film Structures," Journal of Materials Research, 19 [11], 3139-3144, 2004. 
12. D. M. Gage, K. Kim, C. S. Litteken, and R. H. Dauskardt, "The Role of Friction and Loading Parameters on Four-Point Bend Adhesion Measurements," Journal of Materials Research, 2005. In review.

13. M. Lane, A. Vainchtein, H. Gao and and R. H. Dauskardt, "Plasticity Contributions to Interface Adhesion in Thin-Film Interconnect structures," Journal of Materials Research, 15 [12], 2758-2769, 2000.

14. S. Stroband and R. H. Dauskardt, "Interface Separation in Residually Stressed Thin-Film Structures," Interface Science special issue on "Mechanics of Interfaces" 11 (3), 309-317, 2003.

15. S. Stroband and R. H. Dauskardt, "Effect of Barrier Layer Properties on Adhesion in Thin-Film Structures," International Journal of Fracture, 2003. In review.

16. C. S. Litteken, S. Stroband, and R. H. Dauskardt, "Residual Stress Effects on Plastic Deformation and Interfacial Fracture in Thin-Film Structures," Acta Materialia, 2004. In press.

17. R. H. Dauskardt, S.-Y. Kook, A. Kirtikar and K. L. Ohashi, "Adhesion and Progressive Delamination of Polymer/Metal Interfaces," in "High Cycle Fatigue of Structural Materials," Eds. T. S. Srivatsan and W. O. Soboyejo, Proceedings of the Paul C. Paris Symposium, TMS-ASM Publication, 1997.

18. J. M. Snodgrass, S.-Y. Kook, A. Kirtikar and R. H. Dauskardt, "Adhesion and Reliability of Polymer/Inorganic Interfaces in microelectronic Applications," in Proceedings of the 1997 International Mechanical Engineering Congress and Exposition, ASME, Dallas, TX.

19. R. J. Hohlfelder, D. A. Maidenberg, R. H. Dauskardt, Y. Wei, and J. W. Hutchinson, "Adhesion of Benzocyclobutine-Passivated Silicon in Epoxy Layered structures," Journal of Materials Research, 16 [1], 243-255, 2000.

20. Lin, Y., J. Vlassak, T. Tsui, and A. McKerrow. Environmental effects on subcritical delamination of dielectric and metal films from organosilicate glass (OSG) thin films. 2003: Warrendale, PA, USA : Mater. Res. Soc, 2003.

21. $\quad$ E. P. Guyer and R. H. Dauskardt, "Fracture of Nanoporous Thin-Film Glasses," Nature Materials, published online, 7 December 2003. In print: 3, 53-57, 2004.

22. Guyer, E.P. and R.H. Dauskardt. Effect of Aqueous Solution Chemistry on the Accelerated Cracking of Lithographically Patterned Arrays of Copper and Nanoporous Thin-Films. in Materials Research Society. 2004. San Francisco, CA.

23. V. C. Jew and R. H. Dauskardt, "Subcritical Crack Growth and Reliability of Calcium Phosphate Synthetic Bone Cement," Biomaterials, 2005. To be submitted.

24. C.L. Muhlstein, S.B. Brown, and R.O. Ritchie, "High-Cycle Fatigue of Single Crystal Silicon Thin Films." J. MEMS. 2001 (in press).

25. C.L. Muhlstein, S.B. Brown, and R.O. Ritchie, "High-Cycle Fatigue and Durability of Polycrystalline Silicon Think Films in Ambient Air." Journal of Sensors \& Actuators. 2001 (in press). 
26. A. G. Evans, "Fatigue in Ceramics," Int. J. Fract., 16 [6] 485-98 (1980).

27. A.G. Evans and E.R. Fuller, 'Crack Propagation in Ceramic Materials under Cyclic Loading Conditions," Met. Trans. 5, 27-33 (1974).

28. A. M. Fitzgerald, R. H. Dauskardt, and T. W. Kenny, Sensors and Actuators:A 83, 194 (2000).

29. A.M. Fitzgerald, R.H. Dauskardt, and T.W. Kenny, "Stress Wave Interference Effects during Fracture of Silicon Micromachined Specimens," Journal of Experimental Mechanics, 43 [3] 317 - 322, 2003. 